\title{
A COMPARISON BETWEEN PREVENTATIVE AND CURATIVE SOIL TREATMENTS FOR CONTROL OF FUNGUS GNATS
}

\author{
N.A. MARTIN and P.J. WORKMAN \\ New Zealand Institute for Crop \& Food Research Limited, \\ Private Bag 92 169, Auckland
}

\begin{abstract}
Preventative and curative insecticide treatments were assessed for efficacy against fungus gnats (Bradesia paupera) in potting soil. Insecticide solutions $(20 \mathrm{ml}$ per $250 \mathrm{ml}$ of growing medium per $100 \mathrm{~mm}$ diameter pot) were either mixed into the potting medium before planting tobacco seedlings (preventative treatment) or watered into the pots immediately after planting into medium infested with fungus gnat larvae (curative treatment). Preventative treatments of fipronil $(0.1,0.2$ or $0.4 \mathrm{~g} /$ litre) and diflubenzuron $(0.25 \mathrm{~g} /$ litre) were equally effective over 4 weeks at preventing plant loss, maintaining plant vigour (measured by the length of the longest leaf) and keeping fungus gnat larval numbers low $(<1$ per $25 \mathrm{ml}$ medium versus 18 per $25 \mathrm{ml}$ from watertreated medium). In the curative trial, $70 \%$ of the water-treated plants died, compared to $60 \%$ of the diflubenzuron and $<7 \%$ of the fiproniltreated plants. Vigour of the surviving plants was similarly affected, but larval numbers had declined in all treatments from day 0 to 14 days after treatment. Measuring the effect of treatments on a susceptible test plant and on larvae in the growing medium were both important for determining the efficacy of treatments for fungus gnat control.
\end{abstract}

Keywords: Sciaridae, Diptera, insecticide efficacy, Bradesia paupare.

\section{INTRODUCTION}

Larvae of some species of fungus gnats, (Diptera: Sciaridae), are associated with damage to the roots of seedlings and to cuttings (Hussey et al. 1969; Binns 1981). Adults of Bradesia paupare (Tuomikoski), have been found in New Zealand nurseries and are known to damage plants. Fungus gnats are controlled overseas with drenches of insecticides or with nematodes (Gill 1996). In New Zealand, nematodes are not available commercially for fungus gnat control, and no insecticide is registered for this purpose although diflubenzuron (Dimlin $25 \mathrm{~W}$ ) is used at concentrations recommended for mushroom production. Assessment of the efficacy of treatments against fungus gnats is usually based on indirect methods, i.e. determining the numbers of adult flies emerging from plant pots, adults caught on sticky traps or larvae caught under potato disc baits (Gouge and Hague 1995; Harris et al. 1995), rather than determination of numbers of larvae in growing media. The present paper reports methods developed for assessing the efficacy of fipronil (Regent 200SC) as a preventative and curative treatment for control of fungus gnats through measuring larvae in the potting medium and growth and mortality of tobacco seedlings.

\section{Preventative treatment}

\section{MATERIALS AND METHODS}

For each treatment 6 litres of potting medium plus $120 \mathrm{~g}$ of blood and bone and $600 \mathrm{ml}$ of pesticide solution (or water) were mixed together, and $250 \mathrm{ml}$ of mixture were placed in each of 24 pots ( $100 \mathrm{~mm}$ diameter). One tobacco seedling was planted in each pot. After planting, the pots were placed in an isolated greenhouse unit with 
a source of fungus gnats. The pots from each treatment were arranged in eight groups of three pots, each group of three being a plot in a replicate (eight replicates in all). The 15 (three $x$ five treatments) pots in a replicate were grouped around three pots (source of fungus gnats) with one of each treatment around each source. Each pot was placed on an individual saucer to retain any liquid when watered with $50 \mathrm{ml}$ water twice a week. The medium was treated and seedlings planted on 17 April 1997.

\section{Curative treatment}

Pots with untreated medium and without seedlings were placed in a greenhouse unit with a source of fungus gnats. After 14 days, each pot was planted with a tobacco seedling and watered with $20 \mathrm{ml}$ of pesticide solution or water. The pots, each with a saucer, were arranged as above and given $50 \mathrm{ml}$ of water twice weekly after planting. The pots were filled on 17 April 1997, planted and treated on 1 May 1997. Each of the five treatments was replicated eight times. There were three pots per "plot". Twenty four (eight $\mathrm{x}$ three) extra pots were put into the greenhouse unit with the rest during the sciarid infestation stage. These pots were allocated to each replicate and used for the pretreatment assessment.

\section{Assay system}

Flower pots with heavy populations of B. paupera were established in two greenhouse compartments. Voucher specimens of the flies have been deposited in the National Arthropod Collection, Mount Albert Research Centre, Auckland.

Three concentrations of fipronil (Regent 200 SC - $200 \mathrm{~g}$ fipronil/litre) were compared with a standard, diflubenzuron (Dimlin $25 \mathrm{~W}-250 \mathrm{~g}$ diflubenzuron $/ \mathrm{kg}$ ) and water control (Tables 1-4).

The peat-bark-pumice potting medium was amended with $20 \mathrm{~g}$ of blood and bone per litre of medium in order to get a good fungus gnat infestation. The composition of the unamended media was: peat (40\%), bark 0-8 fines (30\%), pumice AP6, $(30 \%)$, dolomite, (4 kg), agricultural lime, (4 kg), Osmocote 3-4 (1.5 kg), $\mathrm{MgSO}_{4}(500 \mathrm{~g})$, gypsum $(500 \mathrm{~g}), \mathrm{KNO}_{3}(300 \mathrm{~g})$, trace element mix (200 g), $\mathrm{FeSO}_{4}(125 \mathrm{~g})$

The tobacco seedlings cv "Brazilian blend" were from a line maintained by Crop \& Food Research.

\section{Assessments}

Mortality of plants and vigour of survivors which was assessed by measuring the length of the longest leaf on each plant, was recorded for the preventative trial $5,9,16$ and 23 days after treatment and for the curative trial 0, 7, 14 and 21 after treatment.

Fungus gnat larvae were driven from samples of growing medium by heat into water-filled funnels using a method modified from Martin (1975). This was done three times, at 14, 21 and 28 days and 7, 14 and 21 days for the preventative and curative treatments respectively. On each occasion only one pot per replicate of each treatment was sampled. No pot was sampled twice. Four samples (total volume $=25 \mathrm{ml}$ ) of potting medium from the surface of each pot were placed into a container $(55 \mathrm{~mm}$ diameter, $27 \mathrm{~mm}$ high) with cloth netting ( $2 \mathrm{~mm}$ diameter mesh) over the base. This was placed in a glass funnel filled with water that almost touched the cloth netting and with a heat source (15 watt light bulb) above each funnel. The voltage was increased in steps over 2 days until the potting medium was dry. The water in the funnel was run into a beaker and after examination under a microscope, the numbers of fungus gnat and other fly larvae were recorded.

\section{Data analysis}

All analyses were carried out with Genstat 5 release 4.1 (Genstat Committee, 1998). The mean length of the longest leaf of each plants from each treatment within each block was examined for each week separately using Analysis of Variance (with missing value estimation for dead plants where necessary). The numbers of dead plants were examined with logistic regression (McCullagh and Nelder 1989). The post planting larval counts were examined separately for each week, and the pre-planting counts for the relevant set included in these analyses. The larval counts were examined with log-linear modelling (McCullagh and Nelder 1989). 


\section{Plant death}

\section{RESULTS}

During the 4 week preventative trial, plants died only in the water (experimental control) treatment (four by day 14 and nine by day 23). However, many more seedlings died, most in the first week, when they were planted into fungus gnat infested soil (curative treatment) (Table 1). The proportion of dead plants was similar in the water and diflubenzuron treatments and higher $(\mathrm{P}<0.05)$ than in all fipronil treatments. The low numbers of dead plants in the fipronil-treated pots suggests that all concentrations of this insecticide gave quick protection to the seedlings.

TABLE 1: Percent mortality of tobacco seedlings during 7 days after curative insecticide treatments were applied. Means are adjusted for block differences. Confidence intervals $(95 \%)$ in parentheses. Number of plants per treatment $=24$.

\begin{tabular}{lccccc}
\hline $\begin{array}{l}\text { Time after } \\
\text { treatment }\end{array}$ & $\begin{array}{c}\text { Water } \\
\text { control }\end{array}$ & 0.1 & 0.2 & 0.4 & $\begin{array}{c}\text { Diflubenzuron } \\
(0.25 \text { g ai/litre })\end{array}$ \\
\hline 7 days & 74 & 6.3 & 3.0 & 6.3 & 60 \\
& $(50,89)$ & $(1.3,26)$ & $(0.3,23)$ & $(1.3,26)$ & $(36,80)$ \\
\hline
\end{tabular}

\section{Plant vigour}

By day 9, plants in the preventative treatments had bigger $(\mathrm{P}<0.05)$ leaves than water-treated plants (Table 2). There were no statistically significant differences between the four insecticide treatments at the end of the trial. In the curative trial, the surviving water-treated plants had smaller $(\mathrm{P}<0.05)$ leaves than the fipronil treated plants 14 days after planting, and smaller $(\mathrm{P}<0.05)$ leaves than all treated plants after 21 days. By day 21 , leaves in the fipronil-treated plants were longer $(\mathrm{P}<0.05)$ than diflubenzuron-treated plants.

TABLE 2: Mean lengths of longest leaves $(\mathrm{mm})$ of surviving tobacco seedlings after preventative and curative insecticide treatments. Initial number of seedlings per treatment $=24$.

\begin{tabular}{|c|c|c|c|c|c|}
\hline \multirow{2}{*}{$\begin{array}{l}\text { Time after } \\
\text { treatment }\end{array}$} & \multirow{2}{*}{$\begin{array}{l}\text { Water } \\
\text { control }\end{array}$} & \multicolumn{2}{|c|}{ Fipronil (g ai/litre) } & \multirow{2}{*}{$\begin{array}{l}\text { Diflubenzuron } \\
(0.25 \mathrm{~g} \text { ai/litre })\end{array}$} & \multirow{2}{*}{$\begin{array}{l}\text { LSD } \\
(5 \%)\end{array}$} \\
\hline & & $\begin{array}{ll}0.1 & 0.2\end{array}$ & 0.4 & & \\
\hline
\end{tabular}

\section{Preventative treatment}

$\begin{array}{lrrrrrr}5 \text { days } & 6 & 6 & 6 & 6 & 7 & 0.9^{1} \\ 9 \text { days } & 11 & 15 & 17 & 16 & 15 & 3.0^{1} \\ 16 \text { days } & 14 & 41 & 43 & 42 & 39 & 6.9^{1} \\ 23 \text { days } & 12 & 71 & 77 & 77 & 72 & 10.3^{1}\end{array}$

\section{Curative treatment}

\begin{tabular}{lrrrrrr} 
Day 0 & 4 & 4 & 4 & 4 & 4 & $0.5^{1}$ \\
7 days & 6 & 6 & 7 & 8 & 7 & $2.0^{2}$ \\
14 days & 9 & 18 & 18 & 22 & 14 & $5.2^{2}$ \\
21 days & 13 & 35 & 40 & 47 & 26 & $8.9^{3}$ \\
\hline
\end{tabular}

Degrees of freedom $={ }^{1} 28 ;{ }^{2} 23 ;{ }^{3} 22$

\section{Fungus gnat larvae}

All preventative treatments of fipronil and diflubenzuron reduced $(\mathrm{P}<0.05)$ fungus gnat larval populations for the 4 week trial (Table 3 ). 
TABLE 3: Mean numbers of fungus gnat larvae per pot $(25 \mathrm{ml}$ of potting medium from the surface of each pot) from the preventative insecticide treatments. Means are adjusted for block differences, and $95 \%$ confidence interval are indicated in parentheses. Number of pots per treatment $=8$.

\begin{tabular}{cccccc}
\hline $\begin{array}{l}\text { Time after } \\
\text { treatment }\end{array}$ & $\begin{array}{c}\text { Water } \\
\text { control }\end{array}$ & 0.1 & 0.2 & 0.4 & $\begin{array}{c}\text { Diflubenzuron } \\
(0.25 \text { g ai/litre })\end{array}$ \\
\hline Week 2 & 10 & 0.9 & 0.8 & 0.0 & 0.6 \\
& $(6,17)$ & $(0.3,3)$ & $(0.3,3)$ & $(0.0, *)$ & $(0.1,2.3)$ \\
Week 3 & 33 & 0.3 & 0.9 & 0.4 & 0.2 \\
& $(28,38)$ & $(0.1,1.1)$ & $(0.4,1.9)$ & $(0.1,1.2)$ & $(0.0,1.0)$ \\
Week 4 & 18 & 0.3 & 0.4 & 0.0 & 0.3 \\
& $(15,23)$ & $(0.1,1.0)$ & $(0.2,1.2)$ & $(0.0, *)$ & $(0.1,0.9)$ \\
\hline
\end{tabular}

* = no valid upper value

The curative trial had higher $(\mathrm{P}<0.05)$ numbers of fungus gnat larvae at time of planting (Table 4) than in all post-treatment samples. The decline in populations in the control pots may have been due to soil disturbance (planting seedlings) or changes in the greenhouse environment. Mean larval numbers were significantly $(\mathrm{P}<0.05)$ lower in the fipronil treated pots than in the control pots in weeks 1,2 and 3. Larval numbers in the diflubenzuron treated pots were similar to the control plots in week 1 , but significantly $(\mathrm{P}<0.05)$ lower in weeks 2 and 3 . There were no significant differences between diflubenzuron and fipronil in weeks 2 and 3.

TABLE 4: Mean numbers of fungus gnat larvae per pot $(25 \mathrm{ml}$ of potting medium from the surface of each pot) from the curative insecticide treatments. Means are adjusted for block differences and 95\% confidence interval are indicated in parentheses. Number of pots per treatment $=8$. The pretreatment samples were taken from all pots just prior to treatment and planting

\begin{tabular}{ccccccc}
\hline $\begin{array}{l}\text { Time after } \\
\text { treatment }\end{array}$ & $\begin{array}{c}\text { Pre- } \\
\text { treatment }\end{array}$ & $\begin{array}{c}\text { Water } \\
\text { control }\end{array}$ & 0.5 & 1 & 2 & $\begin{array}{c}\text { Diflubenzuron } \\
(0.25 \text { g ai/litre })\end{array}$ \\
\hline Week 1 & 47 & 5.0 & 0.8 & 0.3 & 0.2 & 2.4 \\
& $(39,57)$ & $(2.9,8.4)$ & $(0.2,2.9)$ & $(0.0,2.5)$ & $(0.0,2.6)$ & $(1.1,5.0)$ \\
Week 2 & 22 & 3.6 & 0.5 & 0.2 & 0.5 & 0.3 \\
& $(16,29)$ & $(2.1,6.2)$ & $(0.1,2.0)$ & $(0.0,1.7)$ & $(0.1,2.0)$ & $(0.1,1.8)$ \\
Week 3 & 16 & 4.1 & 0.2 & 0.2 & 0.7 & 0.2 \\
& $(11,23)$ & $(2.2,7.7)$ & $(0.0,2.5)$ & $(0.0,2.8)$ & $(0.2,2.8)$ & $(0.0,2.5)$ \\
\hline
\end{tabular}

\section{DISCUSSION}

The preventative treatments of fipronil and diflubenzuron gave better protection of tobacco seedlings from fungus gnats than the curative treatments. The preventative treatments clearly prevented fungus gnat infestations building up in the four weeks after treatment. In the preventative treatment, there were no differences between insecticide treatments for both numbers of larvae and plant growth over the short time scale of the experiment.

Where seedlings were planted into fungus gnat-infested medium (curative treatment trial), fewer plants died in the fipronil- than the diflubenzuron-treated pots, and the surviving fipronil-treated plants were more vigorous than those treated with 
diflubenzuron. This suggests that fipronil stopped the fungus gnat larvae feeding more rapidly than diflubenzuron.

In the curative trial there was a natural decline in populations of fungus gnat larvae during the 14 days after treatment which masked any direct effect of the insecticides on the larvae. This phenomenon emphasises the need to assess effects of treatments both on host plants and pest insects. Further more, the protocol for the curative treatment trial could be improved by assessing larval populations 3 days after treatment to detect short-term changes brought about by the treatments.

Fungus gnats can damage both seedlings and cuttings (N. Martin pers. comm.). Small seedlings show the effects of root damage more quickly than cuttings. This made seedlings particularly suitable for assessing the differences between the curative insecticide treatments. It is unlikely that indirect measures of fungus gnat populations (e.g. adults caught on sticky traps or emerging from pots) would have shown differences between treatments. Trapping of larvae under potato discs is also an indirect measure because it depends on larval behaviour which can be influenced by sub-lethal effects of pesticides and environmental conditions. The techniques reported here, used together, provide a sound method for assessing insecticides for efficacy against fungus gnats.

Blood and bone needed to be added to the growing medium to encourage fungus gnats for the experiments. Conversely, to discourage fungus gnats blood in plant growing media blood and bone and possibly other organic fertilisers should not be used. Plant pots nearest the sunniest end of the greenhouse tended to have fewer larvae than other pots. The surface soil in these pots dried out more quickly. Allowing the soil surface to dry between watering is a recommended way to reduce the risk from fungus gnats (Martin 1996) and can be combined with other techniques (Martin 1996) to minimise fungus gnat problems.

\section{CONCLUSION}

The preventative treatments, fipronil and diflubenzuron, gave better protection to seedlings than the curative treatments, and they prevented fungus gnat infestations from developing in the potting medium. Where fungus gnats were already infesting the medium, fipronil gave better protection to plants than diflubenzuron, presumably though quicker control of fungus gnat larvae. The risk of damage to plants by fungus gnats can be reduced by avoiding use of additional organic matter, e.g. blood and bone, and by allowing the surface of plant pots to dry out between waterings. In trials assessing the efficacy of pesticides for fungus gnat control, it is useful to measure the direct effects both on host plants and on fungus gnat larvae.

\section{ACKNOWLEDGEMENTS}

Ruth Butler (Crop \& Food Research) for statistical analysis and constructive comment; Guy Penny for technical help and suggestions.

\section{REFERENCES}

Binns, E.S., 1981. Fungus gnats (Diptera: Mycetophyllidae/Sciaridae) and the role of mycophagy in soil: a review. Rev. Ecol. Biol. Sol 18 (1): 77-90.

Genstat Committee, 1998. Genstat 5 Release 4.1 Reference Manual Supplement. $\mathrm{NaG}$, Oxford, UK. 229 pp.

Gill, S., 1996 Fungus gnats: beware of this pest from the dark side. Greenhouse Management and Production (December 1996): 22-24.

Gouge, D.H. and Hague, N.G.M., 1995. Glasshouse control of fungus gnats, Bradesia paupera on fuchsias by Steinernema feltiae. Fundament. Appl. Nematol. 18(1): 77-80.

Harris, M.A., Oetting, R.D. and Gardener, W.A., 1995. Use of entomopathogenic nematodes and a new monitoring technique for control of fungus gnats, Bradesia coprophila (Diptera: Sciaridae), in floriculture. Biol. Control 5: 412-418.

Hussey, N.W., Read, W.H. and Hesling, J.J., 1969. The pests of protected cultivation: The biology and control of glasshouse and mushroom pests. Edward Arnold, London. 404 pp. 
Martin, N.A., 1975. Effect of four insecticides on the pasture ecosystem: IV. Enchytraeidae and Diptera larvae heat-extracted in water-filled funnels. N.Z. J. Agric. Res. 18: 313-315.

Martin, N.A., 1996. On the cutting edge of controlling fungus gnats. Flowers New Zealand April 1996: 14-15.

McCullagh, P. and Nelder, J.A., 1989. Generalised Linear Models ( $2^{\text {nd }}$ edition). Chapman and Hall, London. 